\title{
Atividade alimentar diária da cabrinha Prionotus punctatus (Teleostei: Triglidae) do litoral de Ubatuba, Brasil
}

\author{
Lucy Satiko Hashimoto SOARES \& Ronald APELBAUM*
}

Instituto Oceanográfico da Universidade de São Paulo

(Caixa Postal 66149, 05389-970 Sāo Paulo, SP, Brasil)

\begin{abstract}
- Abstract: The feeding habits and the diel feeding periodicity of the searobin Prionotus punctatus were investigated at Ubatuba region $\left(22^{\circ} 30^{\circ} \mathrm{S}\right)$ in the western South Atlantic. The samples were collected during consecutive $3 \mathrm{~h}$ periods over 24 $\mathrm{h}$ in January, 1987 and July and December, 1988. The diel feeding activity analysis indicated that Prionotus punctatus was a daytime feeder with afternoon tendency, permitting to bring up the hypothesis of the circadian rythm. The main food items were Portunidae crabs in Summer, and Portunidae and Penaeidae shrimps in Winter. The diet composition was very similar during the feeding activity time in Winter (July 1988), whereas it showed some variation in Summer (January 1987 and December 1988).

- Resumo: Com o objetivo de se identificar a cronologia alimentar e comparar a composição dos conteúdos estomacais ao longo do dia foram obtidas amostras de Prionotus punctatus na plataforma interna ao largo de Ubatuba (SP), Brasil, durante o ciclo diário em janeiro/87, julho/88 e dezembro/88. As amostras foram obtidas com rede de arrasto de fundo, a intervalos de aproximadamente 3 horas. Através do acompanhamento da frequêencia relativa dos graus de repleção, dos indicadores de repleção, do número médio de presas frescas evidenciou-se nitidamente que Prionotus punctatus possui hábito alimentar diurno com tendência vespertina, podendo-se levantar a hipótese de ritmo circadiano na atividade alimentar. A composição dos conteúdos consistiu, principalmente de jovens de siris Portunus spinicarpus no verāo (janeiro/87 e dezembro/88), e de jovens de Portunidae e camarōes Penaeidea (Sicyonidae e Pleoticus mulleri) no inverno (julho/88). A composição foi altamente similar durante a fase de atividade alimentar no inverno, enquanto que apresentou variação tanto no verāo/87 quanto no verão/88.

- Descriptors: Marine fish, Triglidae, Prionotus punctatus, Diel feeding, Stomach Contents, Brazilian Southeastern coast.

- Descritores: Peixe marinho, Triglidae, Prionotus punctatus, Atividade alimentar diária, Conteúdos Estomacais, Sudeste do Brasil.
\end{abstract}

\section{Introdução}

Este trabalho é parte de um amplo estudo desenvolvido

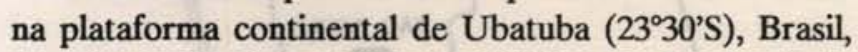
através do Projeto Integrado "Utilizaçāo Racional de Ecossistemas da Regiāo Tropical Brasileira, Estado de São Paulo", cuja meta foi a de obter um conhecimento

(*) Estagiário do IOUSP, bolsista do CNPq. Contr. $n^{e} 762$ do Inst. oceanogr. da Usp. aprofundado da estrutura e dos fenômenos básicos que expliquem seu funcionamento. Aborda aspectos da estrutura trófica de Prionotus punctatus e teve como objetivos identificar o padrão de atividade alimentar diária e comparar a composição do alimento nos diferentes períodos do ciclo diário.

Prionotus punctatus peixe Scorpaeniformes da família Triglidae, conhecida popularmente por cabrinha, é uma espécie demersal amplamente distribuída no Atlântico Ocidental, desde a América Central até Argentina. 
Comum em todo o litoral brasileiro, é encontrada em fundos de areia e lama e também em poças da zona entre-marés e nas proximidades de estuários (Figueiredo \& Menezes, 1980). Na plataforma interna ao largo de Ubatuba foi classificada quanto à ocupação do sistema como permanente, ocorrendo nas quatro estaçōes do ano. É uma espécie importante na trama trófica do sistema, estando incluída entre as 22 espécies dominantes dentre as 171 espécies demersais registradas, ocupando toda a área e a utilizando, aparentemente, na fase de crescimento e de maturaçāo. Sofre variaçāo intra-anual ocorrendo com maior abundância nas estações com massas de água mais quentes (outono-inverno) em comparaçāo com às de águas mais frias (primavera-verāo) (Vazzoler et al., 1988; Rocha, 1990).

Com relação à alimentação da espécie há estudos sobre a composição do alimento realizados no litoral de Ubatuba (Braga \& Braga, 1987; Soares et. al., 1993) e no litoral do Rio Grande do Sul (Teixeira \& Haimovici, 1989), e análises sobre a atividade alimentar nesta última região.

Este é um estudo pioneiro sobre a alimentação da espécie realizado com coletas efetuadas em estaçāo fixa, ao longo do ciclo diário e, que vem acrescentar conhecimentos que permitem interpretar as inter-relaçōes tróficas da espécie com as presas ao longo do dia e, levantar hipótese acerca do ritmo alimentar.

\section{Material e métodos}

As amostras de peixes foram obtidas na plataforma interna do sistema costeiro de Ubatuba, Estado de São Paulo (Fig. 1) em um ciclo diário no período de 08 a 10/01/87 (verão/87) e em dois ciclos diários consecutivos nos períodos de 22 a 24/07/88 (Inverno/88) e de 02 a 04/12/88 (Verāo/88). As coletas foram realizadas com rede de arrasto de fundo (malhagem de $25 \mathrm{~mm}$ entre-nós esticada no ensacador), em arrastos de meia hora, a cada 3 horas.

Os peixes foram congelados imediatamente após a coleta $\left(-15^{\circ} \mathrm{C}\right)$. De cerca de 30 indivíduos de cada amostra, tamanho considerado adequado para este tipo de estudo segundo Livingston (1982) e Macpherson \& Roel (1987), foram obtidos o comprimento total (mm), o peso total (g) e retirados os estômagos, que foram fixados em formalina $10 \%$ neutralizada. Os peixes com os estômagos evertidos ou com presença de alimento na boca foram excluídos das amostras.

Dos estômagos e de seus conteúdos foram obtidos dados de peso do estômago, peso do conteúdo, grau de repleção estomacal, ocorrência e peso dos itens alimentares identificados por grupo taxonômico (Windell \& Bowen, 1978; Berg, 1979; Hyslop, 1980; Bowen, 1983) e estado de digestão dos alimentos.



Fig. 1. Mapa da região de estudo com indicação dos pontos de coleta. 
A identificação taxonômica dos itens alimentares foi baseada em Nonato \& Amaral (1979), Menezes \& Figueiredo (1980), Figueiredo \& Menezes (1980), Barnes (1984) e Williams (1984).

Para registro do grau de repleção estomacal foi usado a seguinte escala: 0 -vazio; 1 -quase vazio, volume do estômago ocupado até $25 \%$; 2 -meio cheio, volume do estômago ocupado em proporção superior a $25 \%$ até $50 \%$; 3-quase cheio, volume do estômago ocupado em proporção superior a $50 \%$ até $75 \% ; 4$ cheio, volume do estômago ocupado em proporção superior a $75 \%$ até $100 \%$.

Para o estado de digestão dos alimentos foi elaborada uma escala organizada com referência nos critérios utilizados por Daan (1973) e Scrimgeour \& Winterbourn (1987): estado 1 (fresco), organismo intacto ou apresentando o tegumento pouco digerido; estado 2 (parcialmente digerido), organismo com o tegumento digerido e com alguma perda de tecido interno ou de apêndices; estado 3 (digerido), organismo em estado avançado de digestão; presença de fragmentos do exoesqueleto ou do endoesqueleto que permitiam a identificação. $O$ estado de disgestão 1 foi também considerado para fragmentos de poliquetas no mesmo estado. $\mathrm{O}$ estado de digestão 2 das presas foi identificado considerando as peculiaridades de cada grupo taxonômico; no caso dos peixes foi considerado o organismo que ainda mantinha a forma, porém já apresentava a epiderme digerida e sem escamas, podendo ter perdido as nadadeiras e parte da musculatura; os crustáceos neste estado de digestão podem apresentar o exoesqueleto, praticamente, preservado; os poliquetas podem apresentar o tegumento parcialmente preservado com presença de parapódios e cerdas. Em relação ao estado de digestāo 3 foi considerada a presença de ossos, cristalinos, otólitos no caso de peixes; de cerdas, mandíbulas, placas anais no caso de poliquetas; fragmentos de exoesqueleto, pereiópodos e pleópodos no caso de crustáceos; de placas calcárias e ossículos no caso de ofiuróides.

A atividade alimentar diária foi analisada e detectada pelo acompanhamento ao longo do ciclo diário dos seguintes indicadores: frequêencia relativa dos graus de repleção; indicadores de repleção estomacal médios IR1 e IR2 (IR1 = peso do conteúdo/peso do peixe; IR2 = peso do estômago cheio/peso do peixe); e número médio de presas frescas (Hyslop, 1980; Weatherley, 1972; Lagardère, 1987; James, 1987, Parrish \& Margraf, 1990; Glova \& Sagar, 1991). Neste último caso foram considerados tanto o total de todas as presas frescas quanto o das presas principais.

As amostras de peixes foram agrupadas por período do dia no qual a coleta foi realizada, considerando-se as efemérides, os principais eventos do ciclo geofísico de 24 horas e o horário padrão brasileiro (Tab. 1).
As análises foram desenvolvidas inicialmente para jovens e adultos e, em seguida para amostra total. A separação em jovens e adultos foi baseada no tamanho da primeira maturação gonadal, determinado por Vazzoler (comun. pess. ${ }^{1}$ ).

As análises de variância paramétrica e não paramétrica (Kruskal-Wallis), assumindo a priori o nível de significância de $5 \%$, foram empregadas para detectar se o período do dia tem efeito significativo sobre o indicador de repleção estomacal e, sobre o número médio de presas frescas (Siegel, 1981; Zar, 1984; Tully \& Ceidigh, 1989; Weatherley, 1989). Quando as médias formaram um grupo heterogêneo, os grupos homogêneos foram obtidos pelo teste de comparaçōes múltiplas, baseados nos intervalos de confiança ao nível de $95 \%$. Através do grupo homogêneo composto pelos maiores valores médios das variáveis consideradas, foram inferidos os períodos de maior atividade alimentar. Estão registrados neste trabalho os valores da inferência estatística paramétrica, pois ambos testes de hipótese apresentaram os mesmos resultados.

No caso dos indicadores de repleção estomacal (IR1, IR2), inicialmente foi verificado o comportamento das duas variáveis, visando a escolha de uma delas para orientar a análise estatística. Nesse sentido foi verificada a existência de correlação entre elas através do cálculo do coeficiente de correlação linear. Considerando a alta correlação entre as duas variáveis, foi aplicado o teste de hipótese ao indicador de repleção IR1.

A comparação da composição do conteúdo alimentar entre os períodos foi realizada para a fase de alimentação do ciclo diário. Foi efetuada através do cálculo de PS (porcentagem de similaridade) de Shorigin (Wallace, 1981; Clark, 1985) das frequências de ocorrência (F\%) e dos pesos porcentuais (P\%) dos itens alimentares, relacionados nas Tabelas 2 a 4. Inicialmente, foram processadas as comparaçōes entre jovens e adultos, em cada período. Valores de similaridade maiores que 60 , foram considerados como altos.

Os dados de temperatura e da salinidade da massa de água de fundo das três épocas de coleta foram plotados em gráficos em relação ao tempo.

\section{Resultados}

Para este estudo foram analisados 494 conteúdos estomacais de Prionotus punctatus, cujas amostras e amplitude de comprimento total dos exemplares estāo apresentadas na Tabela 1.

(1) Vazzoler, A. E. A. de M. Instituto Oceanográfico, 1992. 
Tabela 1. Horário de coleta, número e amplitude de comprimento dos exemplares de Prionotus punctatus das amostras dos ciclos diários dos períodos de 08-10/01/87, de 22 a $24 / 07 / 88$ e de 02 a $04 / 12 / 88$

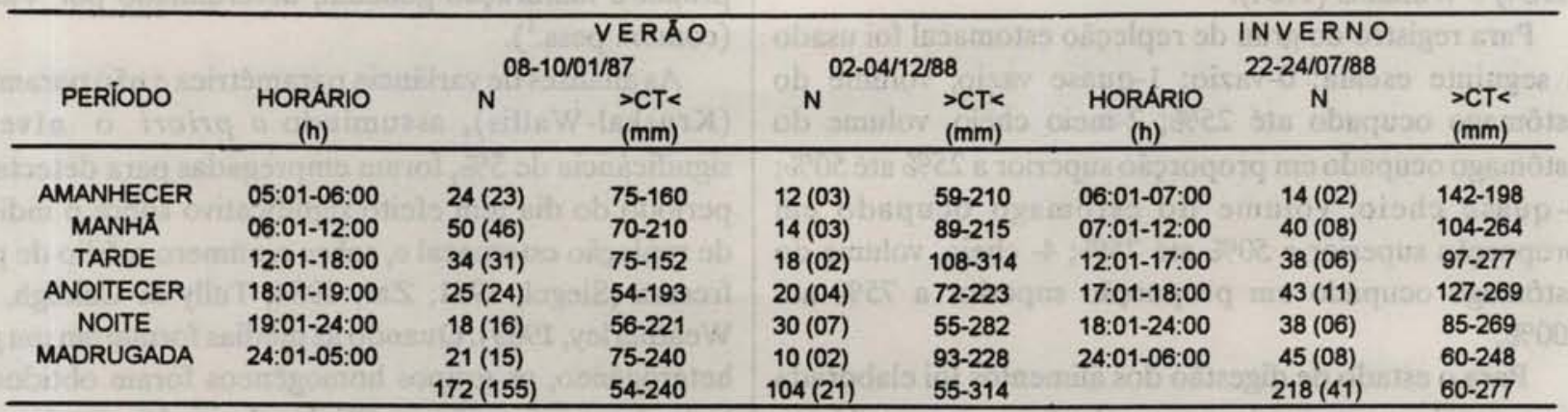

$>\mathrm{CT}<$ amplitude de comprimento dos exemplares

( ) número de jovens

Jovens: $\mathrm{CT}<150 \mathrm{~mm}$

Tabela 2. Frequência de ocorrência $(\mathrm{F} \%)$ e peso porcentual $(\mathrm{P} \%)$ dos itens alimentares dos conteúdos estomacais de Prionotus punctatus no ciclo diário do período de 08 a 10/01/87 (verão/87). Total: $F(\%)$ - número de exemplares; $\mathrm{P}(\%)$ - peso total dos itens.

Porcentagem de Similaridade (PS) entre $F(\%)$ e $P(\%)$ dos itens alimentares $(+)$ na fase de atividade alimentar: $<60 \%$ entre $P(\%)$ da tarde e noite; anoitecer e noite; $>60 \%$ entre as demais combinações

\begin{tabular}{|c|c|c|c|c|c|c|c|c|c|c|c|c|c|c|}
\hline \multirow{3}{*}{$\begin{array}{l}\text { Itens alimentares } \\
\text { POLYCHAETA + }\end{array}$} & \multicolumn{2}{|c|}{$\begin{array}{l}\text { AMANHECER } \\
(05: 01-06: 00 \mathrm{~h})\end{array}$} & \multicolumn{2}{|c|}{$\begin{array}{c}\text { MANHA } \\
(06: 01-12: 00 \mathrm{~h})\end{array}$} & \multicolumn{2}{|c|}{$\begin{array}{c}\text { TARDE } \\
\text { (12:01-18:00 h) }\end{array}$} & \multicolumn{2}{|c|}{$\begin{array}{l}\text { ANOITECER } \\
(18: 01-19: 00 \mathrm{~h})\end{array}$} & \multicolumn{2}{|c|}{$\begin{array}{c}\text { NOITE } \\
(19: 01-24: 00 \mathrm{~h})\end{array}$} & \multicolumn{2}{|c|}{$\begin{array}{l}\text { MADRUGADA } \\
(24: 01-05: 00 \mathrm{~h})\end{array}$} & \multicolumn{2}{|c|}{ TOTAL } \\
\hline & $F(\%)$ & $P(\%)$ & $F(\%)$ & $P(\%)$ & $F(\%)$ & $P(\%)$ & $F(\%)$ & $P(\%)$ & $F(\%)$ & $P(\%)$ & $F(\%)$ & $P(\%)$ & $F(\%)$ & $P(\%)$ \\
\hline & 4.17 & 0.55 & 6.00 & 0.65 & 14.71 & 0.59 & 8,00 & 0.15 & 16.67 & 805 & 4.76 & 1.14 & 872 & 1.56 \\
\hline CRUSTACEA (total) & 95.83 & 99.45 & 100.00 & 69.82 & 97.06 & 90.76 & 100.00 & 97.68 & 83.33 & 33.29 & 47.62 & 81.33 & 80.70 & 75.26 \\
\hline Tanaidacea + & & & 10.00 & 0.11 & 5.88 & 0.08 & & sestive & 5.56 & 0.07 & & & 4.65 & 0.07 \\
\hline Isopoda + & & & & & 11.76 & 0.04 & & & 11.11 & 0.02 & & & 3.49 & 0.01 \\
\hline Gammaridea * & 25.00 & 0.46 & 6.00 & 0.02 & 8.82 & 0.05 & 8.00 & 0.02 & 11.11 & 0.05 & & & 9.30 & 0.05 \\
\hline Cumacea + & 4.17 & 0.09 & 10.00 & 0.06 & 8.82 & 0.23 & 12.00 & 0.22 & 11.11 & 0.20 & & & 8.14 & 0.14 \\
\hline Stomatopoda + & & & & & 8.82 & 0.42 & & & & & & & 1.74 & 0.10 \\
\hline a (total) + & 16.67 & 39.91 & 38.00 & 46.05 & 29.41 & 47.48 & 28.00 & 56.85 & 22.22 & 18.65 & 9.52 & 44.19 & 26.74 & 43.90 \\
\hline N.I. & 8.33 & 12.97 & 0.00 & 4.60 & 17.65 & 8.27 & & & 22.22 & 7.07 & 4.76 & 8.70 & 1047 & 5.69 \\
\hline Sicy & 8.33 & 26.94 & 24.00 & 41.44 & 14.71 & 39.21 & 28.00 & 56.85 & 5.56 & 11.58 & 4.76 & 35.49 & 16.28 & 3821 \\
\hline Canidea (total) * & 8,33 & 4.57 & 4.00 & 0.09 & 5.88 & 0.04 & cheraing & 4180 & 200 & $2 \operatorname{lin}$ & 21010 & bintig & 3.49 & 0.21 \\
\hline Carid & & & 4.00 & 0.09 & 2.94 & & & & & & & & 1.74 & 0.04 \\
\hline Lep & 8.33 & 4.57 & & & 2.94 & 0.04 & -2 & 0 & 2222 & & & & 1.74 & 0.17 \\
\hline Cam & 16.67 & 2.83 & 16.00 & 0.22 & 20.59 & 0.47 & 1 & 0.10 & 22.22 & 0.22 & & & 15.12 & 0.34 \\
\hline (total) * & $\begin{array}{l}62.50 \\
12.50\end{array}$ & 3. & 86.0 & $\begin{array}{r}1979 \\
242\end{array}$ & 88.24 & $\begin{array}{l}37.77 \\
1.86\end{array}$ & 100 & $\begin{array}{r}34.60 \\
3.50\end{array}$ & 66.67 & 12.41 & $\begin{array}{r}33.33 \\
0.59\end{array}$ & $\begin{array}{r}29.84 \\
0.76\end{array}$ & 76.74 & 25.99 \\
\hline N.I. & 12 & 2 & 0 & 2.42 & 9 & 1.86 & 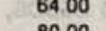 & $\begin{array}{r}3.59 \\
5.05\end{array}$ & 22.22 & 0.29 & 9.52 & 0.76 & 41.86 & 2.06 \\
\hline Portu & 54. & 2 & 84.00 & $\begin{array}{r}10.31 \\
7.00\end{array}$ & 5 & 12.78 & 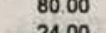 & 25.05 & 61.11 & 10.53 & 33.33 & 21.59 & 70.35 & 14.05 \\
\hline Portunus spinicarpus & 8.33 & 3.20 & 44.00 & 7.06 & 52.94 & 23.03 & 00 & 5.08 & 22.22 & 1.59 & 9.52 & 7.49 & 31.40 & 9.73 \\
\hline $\begin{array}{l}\text { Majidae } \\
\text { Leucosiddae }\end{array}$ & 4.17 & 0.55 & & & 2.94 & 0.10 & $\begin{array}{r}20.00 \\
4.00\end{array}$ & $\begin{array}{l}0.54 \\
0.34\end{array}$ & 98 & 109 & 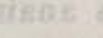 & Bid & $\begin{array}{l}3.49 \\
1.16\end{array}$ & $\begin{array}{l}0.09 \\
0.06\end{array}$ \\
\hline Larva Megalopa + & 95.83 & 17.35 & 74.00 & 3.32 & 70.59 & 256 & 48.00 & 2.61 & 22.22 & 0.27 & 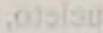 & 30060 & 58.14 & 2.97 \\
\hline Anomura + & & & 2.00 & 0.05 & & & 4.00 & 0.17 & & & & & 1.16 & 0.04 \\
\hline Brachyura/Anomura(") & 4.17 & 0.37 & 4.00 & 0.05 & 52.94 & 1.60 & 36.00 & 3.10 & 50.00 & 1.40 & 19.05 & 7.30 & 25.00 & 1.38 \\
\hline Decapoda N.I. & 20.83 & 0.73 & 2.00 & 0.06 & 2.94 & 0.01 & & & & & & & 4.07 & 0.05 \\
\hline TELEOSTEI (TOTAL) + & & & 24.00 & 29.53 & 35.29 & 8.65 & 36.00 & 2.17 & 22.22 & 58.66 & 9.52 & 17.52 & 22.67 & 23.17 \\
\hline Teleostei N. L. & & & 14.00 & 12.07 & 35.29 & 8.65 & 36.00 & 2.17 & 22.22 & 58.66 & 9.52 & 17.52 & 19.77 & 15.93 \\
\hline Pleuronectiformes & & & 6.00 & 1.70 & & & & & & & & & 1.74 & 0.71 \\
\hline Ponchthys porosissimus & & 69 & 6.00 & 15.76 & 20 & 3 &  & the & 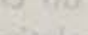 & 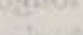 & 6 & 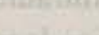 & $\begin{array}{l}1.74 \\
0.58\end{array}$ & 6.54 \\
\hline Escama & & & & & & & & & & & 4.76 & & 0.58 & \\
\hline Restos calcários & $\begin{array}{r}8.33 \\
24\end{array}$ & 1.095 & 16.00 & & 2.94 & & 12.00 & & & & 4.76 & & 8.72 & \\
\hline TOTAL & 24 & & 50 & 12.863 & 34 & 7.307 & 25 & 4.095 & 18 & 4.076 & 21. & 1.575 & 172 & 31.011 \\
\hline
\end{tabular}

Com relação à atividade alimentar diária, os dois indicadores de repleçāo estomacal (IR1 e IR2) se mostraram altamente correlacionados, permitindo o uso de ambos nos estudos de atividade alimentar (verão/87: $\mathrm{r}=0,96$ e $\mathrm{p}=0$; inverno/88: $\mathrm{r}=0,98$ e $\mathrm{p}=0$; verāo/ 88 : $r=0,88$ e $p=0$ ). Estão apresentados, neste trabalho, os resultados da análise estatística do indicador de repleção IR1.
Todas as variáveis utilizadas (indicadores de repleçāo estomacal, grau de repleção, ocorrência e número de presas frescas) apontaram que os grupos de jovens e de adultos desta espécie possuem cronologia alimentar semelhante no ciclo diário, tanto no verão quanto no inverno, podendo ser tratados como uma unidade neste aspecto. Portanto, são analisados neste trabalho os 
Tabela 3. Freqüência de ocorrência $(\mathrm{F} \%)$ e peso porcetual $(\mathrm{P} \%)$ dos itens alimentares dos conteúdos estomacais de Prionotus punctatus no ciclo diário do período de 02 a 04/12/88 (verão/88). Total: $F(\%)$ - número de exemplares; $\mathrm{P}(\%)$ - peso total dos itens.

Porcentagem de Similaridade (PS) entre $F(\%)$ e $P(\%)$ dos itens alimentares $(+)$ na fase de atividade alimentar: <60\% entre $\mathrm{P}(\%)$ da manhã e noite; $>60 \%$ entre as demais combinaçōes

\begin{tabular}{|c|c|c|c|c|c|c|c|c|c|c|c|c|c|c|}
\hline \multirow[b]{2}{*}{ Itens alimentares } & \multicolumn{2}{|c|}{$\begin{array}{l}\text { AMANHECER } \\
(05: 01-06: 00 \mathrm{~h})\end{array}$} & \multicolumn{2}{|c|}{$\begin{array}{c}\text { MANHA } \\
(06: 01-12: 00 \mathrm{~h})\end{array}$} & \multicolumn{2}{|c|}{$\begin{array}{c}\text { TARDE } \\
(12: 01-18: 00 \mathrm{~h})\end{array}$} & \multicolumn{2}{|c|}{$\begin{array}{l}\text { ANOITECER } \\
(18: 01-19: 00 \mathrm{~h})\end{array}$} & \multicolumn{2}{|c|}{$\begin{array}{c}\text { NOITE } \\
(19: 01-24: 00 \mathrm{~h})\end{array}$} & \multicolumn{2}{|c|}{$\begin{array}{l}\text { MADRUGADA } \\
(24: 01-05: 00 \mathrm{~h})\end{array}$} & \multicolumn{2}{|c|}{ TOTAL } \\
\hline & $F(\%)$ & $P(\%)$ & $F(\%)$ & $P(\%)$ & $F(\%)$ & $P(\%)$ & $F(\%)$ & $P(\%)$ & $F(\%)$ & $P(\%)$ & $F(\%)$ & $P(\%)$ & $F(\%)$ & $P(\%)$ \\
\hline POLYCHAETA + & 16.67 & 1.29 & 6.25 & 0.06 & 11.11 & 0.07 & & & 6.67 & 0.06 & & & 6.60 & 0.10 \\
\hline MOLLUSCA (concha) & 8.33 & & & & & & & & 3.33 & & 10.00 & & 2.83 & \\
\hline CRUSTACEA (total) & 91.67 & 94.81 & 93.75 & 99.30 & 100.00 & 94.75 & 95.00 & 100.00 & 90.00 & 98.50 & 50.00 & 100.00 & 89.62 & 97.70 \\
\hline Tanaidacea + & 8.33 & 0.10 & 12.50 & 0.09 & 5.56 & & 5.00 & 0.01 & & & & & 4.72 & 0.02 \\
\hline Gammaridea + & 16.67 & 1.29 & 43.75 & 0.30 & 27.78 & 0.16 & 20.00 & 0.64 & 33.33 & 0.07 & 10.00 & 0.03 & 27.36 & 026 \\
\hline Cumacea + & & & 12.50 & 0.07 & 11.11 & 0.08 & 5.00 & 0.01 & & & 10.00 & 0.10 & 5.66 & 0.04 \\
\hline Stomatopoda + & $36-5=$ & & & & 5.56 & 2.98 & 5.00 & 0.32 & 3.33 & 0.35 & 202 & & 2.83 & 1.02 \\
\hline Penaeidea (total) + & 25.00 & 16.26 & 50.00 & 56.59 & 66.67 & 33.01 & 40.00 & 18.67 & 26.67 & 8.72 & & 8 & 36.79 & 25.00 \\
\hline Penaeidea N.I. & 25.00 & 10.63 & 31.25 & 7.59 & 44.44 & 9.22 & 40.00 & 18.67 & 20.00 & 6.89 & & at & 28.30 & 9.13 \\
\hline Penaeidae & & & 6.25 & 40.45 & & & & & & & & 20 & 0.94 & 6.76 \\
\hline Solenoceridae & 8.33 & 5.64 & 25.00 & 7.62 & 55.56 & 23.78 & & & 6.67 & 1.83 & & & 16.04 & 8.95 \\
\hline Sicyoniidae & 10 & & 6.25 & 0.94 & & & & & & & & & 0.94 & 0.16 \\
\hline Caridea (total) + & 8.33 & 0.54 & 12.50 & 0.43 & 5.56 & 0.22 & $3(x-6)$ & 24 & & Anthos ve & & & 3.77 & 0,16 \\
\hline Caridea N.I. & 8.33 & 0.54 & & & 5.56 & 0.22 & & & & & & & 1.89 & 0.09 \\
\hline Leptochela & & & 12.50 & 0.43 & Fint & $2+30$ & 1129 & & & & & & 1.89 & 0.07 \\
\hline Camarao N.I. & 41.67 & 6.08 & 87.50 & 16.42 & 88.89 & 7.91 & 65.00 & 11.75 & 43.33 & 4.89 & 20.00 & 3.53 & 59.43 & 865 \\
\hline Brachyura (total) + & 58.33 & 70.24 & 81.25 & 24.73 & 100.00 & 40.60 & 90.00 & 58.09 & 90.00 & 75.46 & 40.00 & 93.65 & 82.08 & 55.18 \\
\hline Brachyura N.t. & 25.00 & 12.36 & 25.00 & 2.77 & 38.89 & 2.47 & 45.00 & 5.36 & 36.67 & 5.56 & 30.00 & 15.31 & 34.91 & 4.97 \\
\hline Portunidae N.I. & 25.00 & 40.29 & 56.25 & 13.39 & 38.89 & 10.04 & 50.00 & 27.28 & 23.33 & 13.45 & 10.00 & 78.35 & 34.91 & 19.08 \\
\hline Portunus spinicarpus & 25.00 & 17.25 & & & 38.89 & 19.39 & 15.00 & 15.20 & 46.67 & 45.05 & & & 25.47 & 22.22 \\
\hline Portunus sp & & & 12.50 & 1.31 & & & & & 30.00 & 4.29 & & & 10.38 & 1.53 \\
\hline Majidae & 8.33 & 0.35 & 62.50 & 7.26 & 77.78 & 8.70 & 65.00 & 10.25 & 30.00 & 7.10 & & & 44.34 & 7.39 \\
\hline Brachyura/Anomura (" & & & 31.25 & 0.66 & 38.89 & 2.33 & 65.00 & 10.01 & 53.33 & 8.24 & 10.00 & 2.68 & 39.62 & 488 \\
\hline Decapoda N.I. & & & 12.50 & 0.01 & 33.33 & 7.46 & 15.00 & 0.49 & 46.67 & 0.78 & & at & 23.58 & 2.49 \\
\hline TELEOSTEI + & 16.67 & 3.16 & 6.25 & 0.64 & 22.22 & 5.18 & & & 10.00 & 1.20 & & & 9.43 & 210 \\
\hline Escama & & & & & & & & & 3.33 & & & & 0.94 & \\
\hline Restos calcários & 8.33 & & & & & & & & 6.67 & 0.24 & & 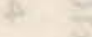 & 283 & \\
\hline Material N. I. & & & & & & Fe & & & 5.67 & & & tx & 283 & 0.10 \\
\hline TOTAL & 12 & 2.023 & 16 & 8.766 & 18 & 15.212 & 20 & 7.521 & 30 & 16.004 & 10 & 2.914 & 106 & 52.440 \\
\hline
\end{tabular}

resultados referentes ao estrato populacional da espécie que ocupa a área de estudo.

Tanto no verāo quanto no inverno $P$. punctatus apresentou uma fase de atividade alimentar e uma fase repouso alimentar. No verão, a fase de atividade alimentar ocorreu entre os períodos da manhã e noite (Figs 2 e 3), e no inverno, entre os da manhã e anoitecer (Fig. 4).

Entre as presas principais, houve indicaçōes de tomada diferencial de braquiúros (entre eles, Portunus spinicarpus) e de megalopa no ciclo diário do verāo/87; os braquiúros ocorreram em maior número nos estômagos dos peixes coletados no período da tarde, enquanto que megalopa ocorreu somente nos períodos do amanhecer e manhã (Fig. 2 c; Tab. 2); camarões foram ingeridos em proporçōes comparáveis ao longo do ciclo diário.

Tanto no inverno/88 quanto no verão/88 ocorreu ingestão mais expressiva de camarōes no período da tarde (Figs 3c e 4c). No verão, os camarōes foram representados, principalmente, pelo peneídeo Solenoceridae (Pleoticus muelleri) (Tab.3) e, no inverno, pelo peneídeo Sicyoniidae e pelo carídeo Leptochela (Tab. 4). Os braquiúros, principalmente Portunidae, foram ingeridos em número constante ao longo da fase de atividade alimentar.

Com relaçâo à composição dos conteúdos estomacais, houve alta similaridade entre os períodos, durante a fase de atividade alimentar (manhā, tarde, anoitecer e noite) do verāo/87, em termos de ocorrência de itens; em termos de peso porcentual verificou-se baixa similaridade entre os períodos noite e tarde e noite e anoitecer (Tab. 2). Nos períodos da manhã, tarde e anoitecer, os camarōes Penaeidea, principalmente Sicyonidae, e os Brachyura, especialmente Portunidae (entre eles Portunus spinicarpus) se destacaram em termos de ocorrência e peso porcentual. No período da noite, Teleostei (entre eles Porichthys porosissimus) foi proporcionalmente mais importante, em termos de peso, do que Penaeidea e Brachyura, fato que explica a dissimilaridade registrada. Megalopa foi importante em termos de ocorrência, porém foi mais representativa em peso ao amanhecer e manhã. Nota-se, também, que nos períodos da tarde e noite houve ocorrência de presas que contribuiram com baixas freqüências.

No verão/88, jovens e adultos de $P$. punctatus apresentaram alta similaridade na composição dos conteúdos estomacais na fase de atividade alimentar (manhā, tarde, anoitecer e noite) sendo, portanto, considerados como uma unidade. Durante esta fase houve alta similaridade na composição dos conteúdos em termos de ocorrência. Com relação ao peso porcentual, há menor similaridade entre os períodos da manhã e noite, manhã e 
Verão - 87

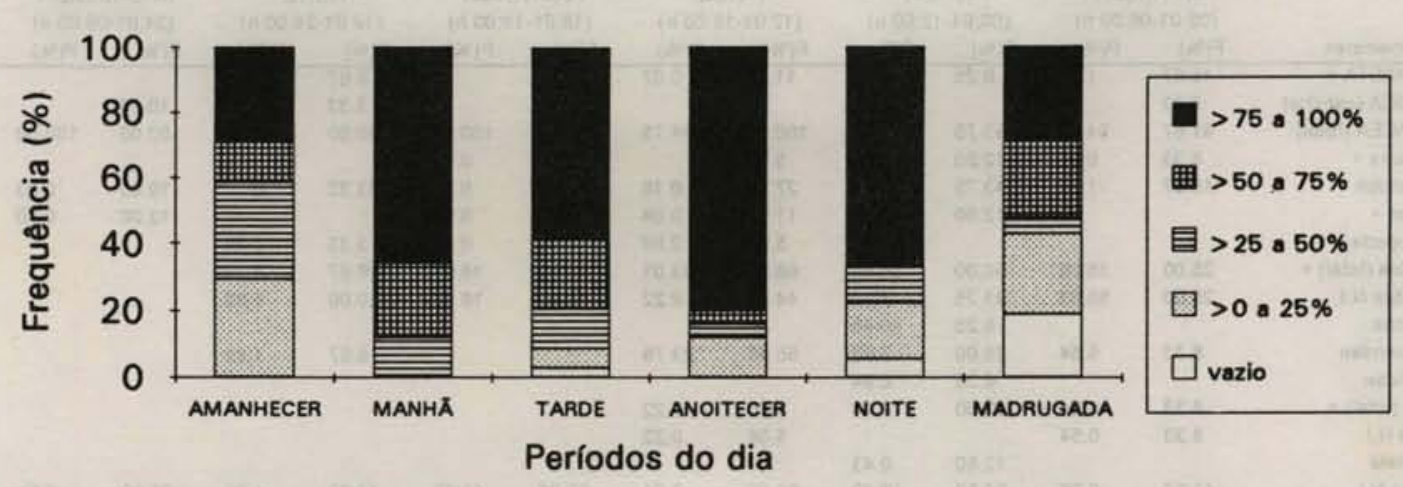

(B)

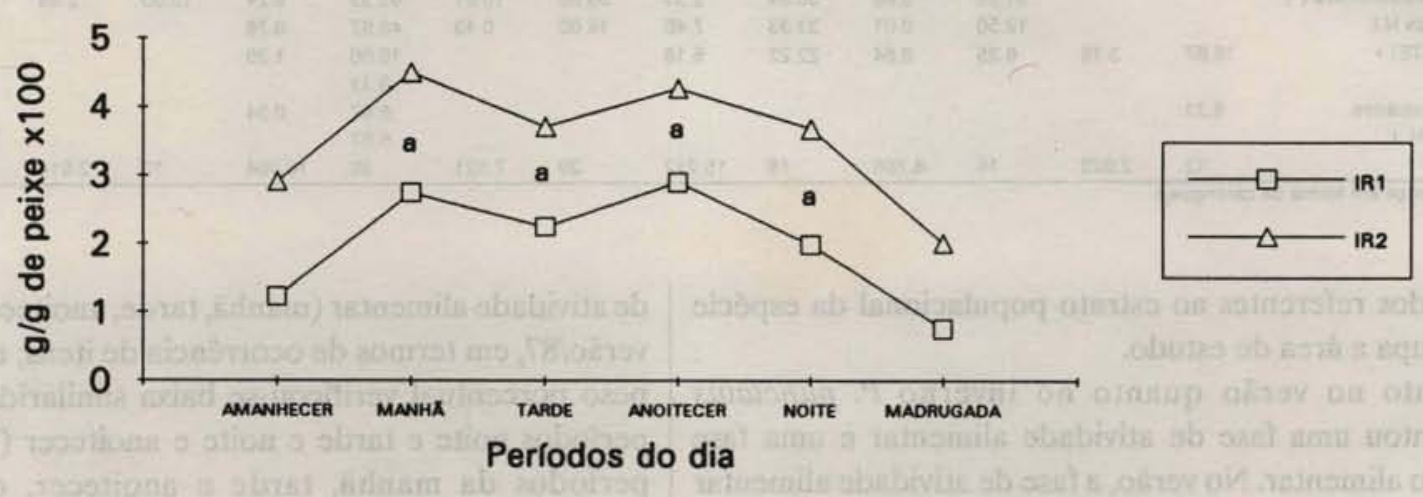

(C)

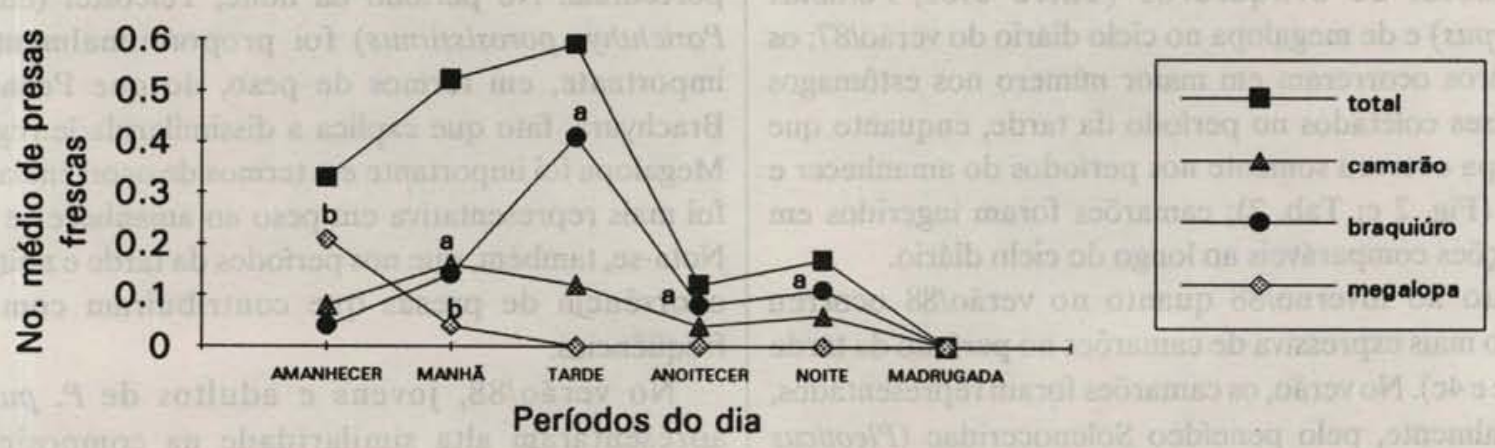

Fig. 2. Frequeência dos graus de repleção estomacal $(A)$, indicadores de repleção médios (B) e número médio de presas frescas (C) dos conteúdos estomacais no ciclo diário do verão/87. As letras indicam grupos homogêneos com os maiores valores médios, de acordo com os resultados da análise de variância e do teste de comparações múltiplas; a ausência de letras indica grupo homogêneo. 


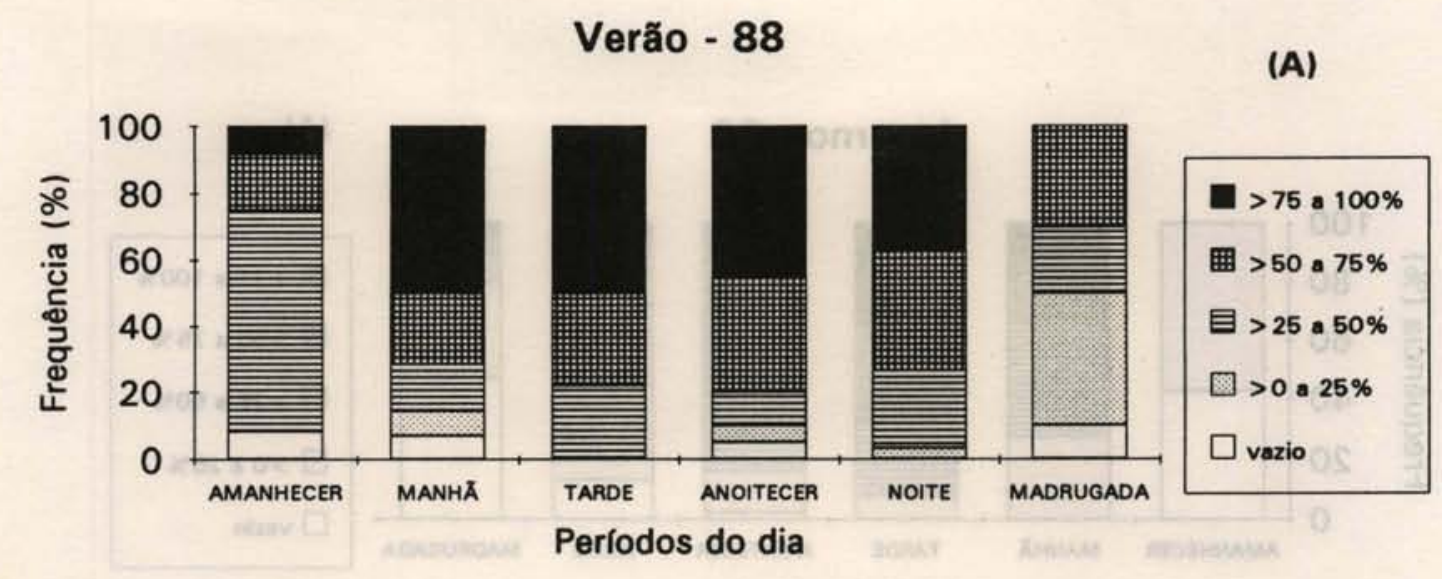

(B)

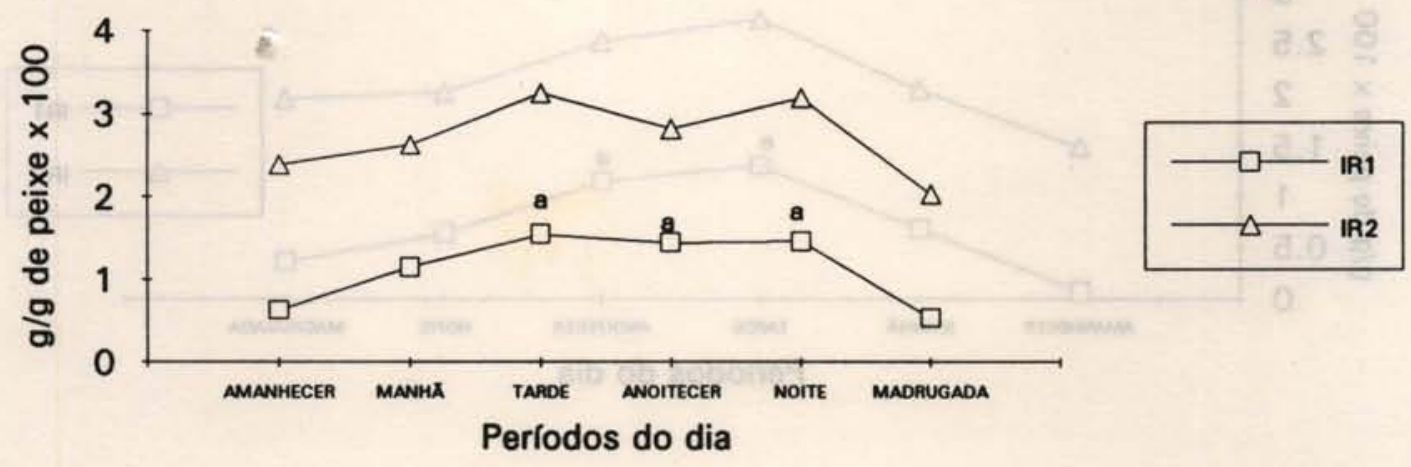

(C)

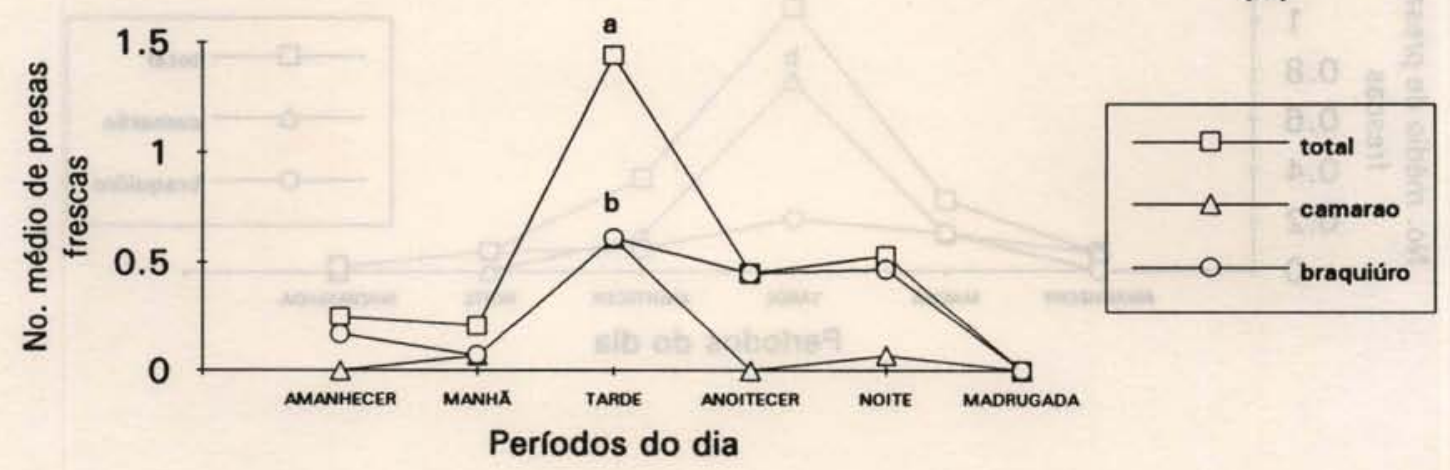

Fig. 3. Freqüência dos graus de repleção estomacal (A), indicadores de repleção médios (B) e número médio de presas frescas (C) dos conteúdos estomacais no ciclo diário do verão/88. As letras indicam grupos homogêneos com os maiores valores médios, de acordo com os resultados da análise de variância e do teste de comparações múltiplas; a ausência de letras indica grupo homogêneo. 

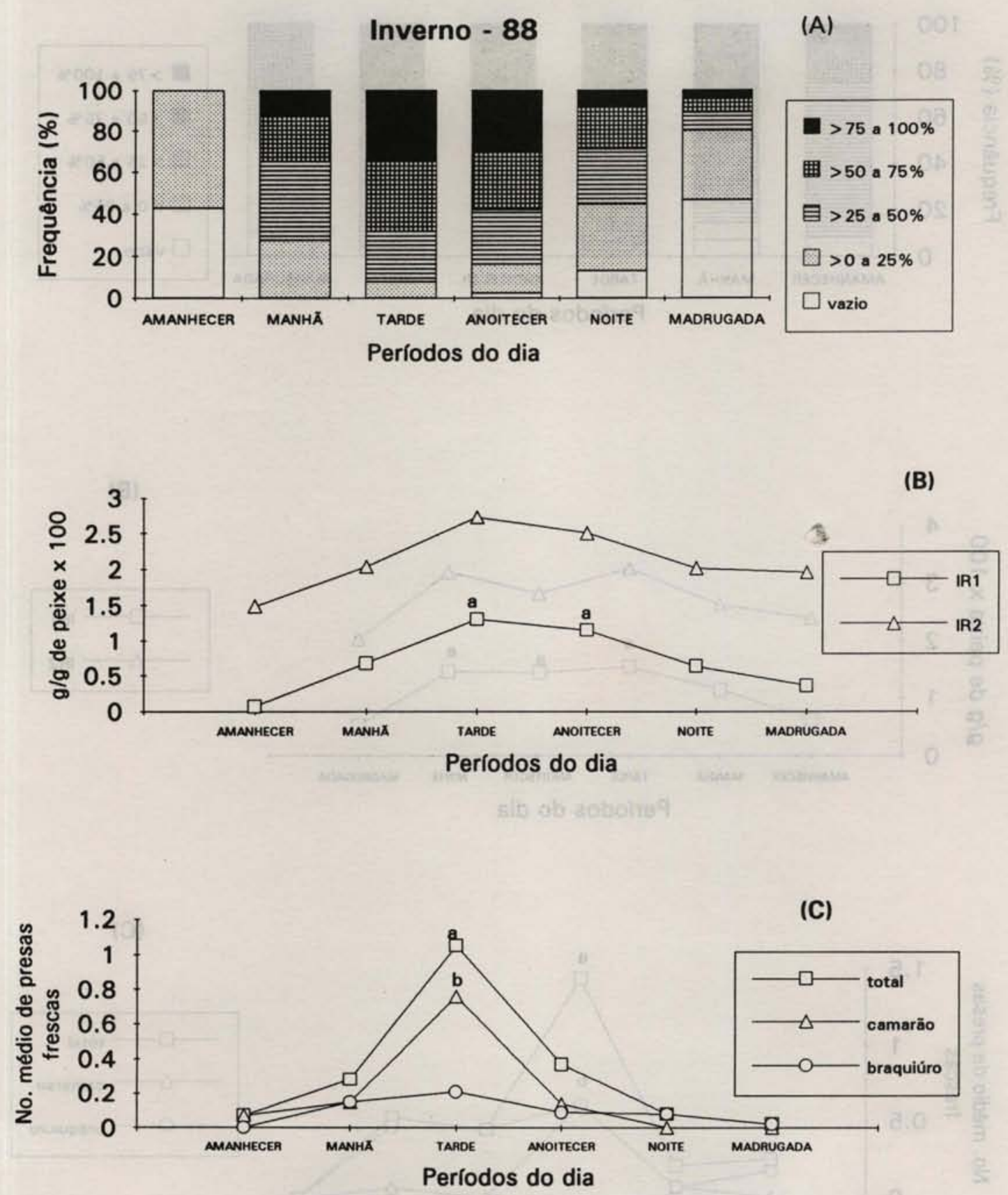

Fig. 4. Freqüência dos graus de repleção estomacal (A), indicadores de repleção médios (B) e número médio de presas frescas (C) dos conteúdos estomacais no ciclo diário do inverno/88. As letras indicam grupos homogêneos com os maiores valores médios, de acordo com os resultados da análise de variância e do teste de comparações múltiplas; a ausência de letras indica grupo homogêneo. 
Tabela 4. Freqüência de ocorrência $(\mathrm{F} \%)$ e peso porcetual $(\mathrm{P} \%)$ dos itèns alimentares dos conteúdos estomacais de Prionotus punctatus no ciclo diário do período de 22 a 24/07/88 (inverno/88). Total: $F(\%)$ - número de exemplares; $P(\%)$ - peso total dos itens.

Porcentagem de Similaridade (PS) entre $F(\%)$ e $P(\%)$ dos itens alimentares (+) na fase de atividade alimentar: todas as combinações

\begin{tabular}{|c|c|c|c|c|c|c|c|c|c|c|c|c|c|c|}
\hline \multirow[b]{2}{*}{ Itens alimentares } & \multicolumn{2}{|c|}{$\begin{array}{l}\text { AMANHECER } \\
\text { (06:01-07:00 } \mathrm{h})\end{array}$} & \multicolumn{2}{|c|}{$\begin{array}{c}\text { MANHA } \\
(07: 01-12: 00 \mathrm{~h})\end{array}$} & \multicolumn{2}{|c|}{$\begin{array}{c}\text { TARDE } \\
(12: 01-17: 00 \mathrm{~h})\end{array}$} & \multicolumn{2}{|c|}{$\begin{array}{l}\text { ANOITECER } \\
(17: 00-18: 00 \mathrm{~h})\end{array}$} & \multicolumn{2}{|c|}{$\begin{array}{c}\text { NOITE } \\
(18: 01-24: 00 \mathrm{~h})\end{array}$} & \multicolumn{2}{|c|}{$\begin{array}{l}\text { MADRUGADA } \\
(24: 01-06: 00 \mathrm{~h})\end{array}$} & \multicolumn{2}{|c|}{ TOTAL } \\
\hline & $F(\%)$ & $P(\%)$ & $F(\%)$ & $P(\%)$ & $F(\%)$ & $P(\%)$ & $F(\%)$ & $P(\%)$ & $F(\%)$ & $P(\%)$ & $F(\%)$ & $P(\%)$ & $F(\%)$ & $P(\%)$ \\
\hline POLYCHAETA + & & +2 & 7.50 & 4.36 & 5.26 & 0.07 & 6.98 & 0.37 & 5.26 & 0.82 & & & 4.59 & 0.87 \\
\hline MOLLUSCA (concha) & 7.14 & & & & & & 4.65 & 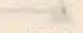 & 2.63 & & 2.22 & & 2.29 & \\
\hline CRUSTACEA (total) & 42.86 & 100.00 & 100.00 & 95.64 & 97.37 & 99.93 & 97.67 & 95.46 & 76.32 & 79.84 & 31.11 & 100.00 & 77.06 & 95.89 \\
\hline Tanaidacea + & & & 5.00 & 0.04 & & & & & & & & & 0.92 & 0.01 \\
\hline Isopoda + & (n) & 1268t & 2.50 & 0.13 & & & & & & al & -1 & & 0.46 & 0.02 \\
\hline Gammaridea + & & & 25.00 & 0.28 & 39.47 & 0.11 & 13.95 & 0.20 & 7.89 & 0.01 & 2.22 & & 16.06 & 0.14 \\
\hline Cumacea + & 7.14 & 1.00 & & & 2.63 & 0.02 & 2.33 & 0.25 & 2.63 & 0.04 & & & 1.83 & 0.08 \\
\hline Stomatopoda + & & & 5.00 & 2.02 & & & & & & & & & 0.92 & 0.30 \\
\hline Penaeidea (total) + & & & 40.00 & 44.45 & 76.32 & 38.68 & 51.16 & 42.60 & 18.42 & 45.06 & 4.44 & 51.14 & 34.86 & 41.87 \\
\hline Penaeidea N.I. & & & 17.50 & 6.76 & 50.00 & 14.52 & 20.93 & 6.61 & 10.53 & 3.07 & & & 17.89 & 9.11 \\
\hline Solenoceridae & & & 5.00 & 1.51 & 2.63 & 0.42 & 2.33 & 0.13 & & & & & 1.83 & 0.44 \\
\hline Sicyonildae & & & 20.00 & 36.18 & 47.37 & 23.73 & 44.19 & 35.88 & 13.16 & 42.00 & 4.44 & 51.14 & 23.85 & 32.32 \\
\hline Caridea (total) + & 21.43 & 19.60 & 70.00 & 13.64 & 76.32 & 7.08 & 34.88 & 3.78 & & & & & 34.40 & 6.03 \\
\hline Caridea N.I. & & & 20.00 & 3.03 & 13.16 & 0.19 & 4.65 & 0.42 & & & & & 6.88 & 0.63 \\
\hline Leptochela & 21.43 & 19.60 & 50.00 & 10.59 & 63.16 & 6.89 & 30.23 & 3.36 & & & & & 27.52 & 5.40 \\
\hline Ogyrididae & & & 2.50 & 0.01 & & & & & & & & & 0.46 & 0.00 \\
\hline Camarăo N.I. & 14.29 & 4.65 & 75.00 & 12.19 & 92.11 & 6.92 & 81.40 & 17.49 & 50.00 & 11.97 & 15.56 & 5.05 & 58.72 & 10.68 \\
\hline Brachyura (total) + & 7.14 & 74.75 & 52.50 & 20.94 & 60.53 & 46.72 & 55.81 & 29.18 & 31.58 & 20.79 & 11.11 & 43.65 & 39.45 & 35.59 \\
\hline Brachyura N.I. & & & 20.00 & 8.45 & 23.68 & 0.58 & 18.60 & 1.84 & 13.16 & 2.34 & 4.44 & 16.29 & 14.68 & 3.30 \\
\hline Portunidae N.I. & 7.14 & 74.75 & 27.50 & 9.32 & 34.21 & 3.82 & 34.88 & 7.13 & 7.89 & 5.59 & 6.67 & 13.25 & 21.10 & 6.59 \\
\hline Portunus spinicarpus & 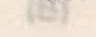 & & & & 2.63 & 0.29 & 16.28 & 13.28 & 5.26 & 4.54 & 2.22 & 14.10 & 5.05 & 4.76 \\
\hline Portunus & & & & & 10.53 & 1.81 & & & & & & & 1.83 & 0.77 \\
\hline Callinectis & & & & & 2.63 & 37.04 & & & & & & & 0.46 & 15.73 \\
\hline Majidae & & 86 & & & & & 2.33 & 1.55 & & det & & & 0.46 & 0.37 \\
\hline Cancridae & & & & & 5.26 & 1.93 & & & & & & & 0.92 & 0.82 \\
\hline Leucosiidae & $\mathrm{at}$ & e6. & 17.50 & 3.17 & 15.79 & 1.25 & 25.58 & 5.38 & 18.42 & 8.32 & & & 14.22 & 3.25 \\
\hline Anomura + & 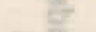 & & & & 7.89 & 0.24 & 2.33 & 0.08 & & & & & 1.83 & 0.12 \\
\hline Brachyura/Anomura ( $\left(^{\circ}\right)$ & Ev & 하랑 & 12.50 & 1.59 & 15.79 & 0.12 & 27.91 & 1.44 & 13.16 & 1.20 & {[} & & 12.84 & 0.77 \\
\hline Decapoda N.I. & $y^{2}=1$ & & 10.00 & 0.36 & 10.53 & 0.05 & 44.19 & 0.45 & 18.42 & 0.76 & 4.44 & 0.16 & 16.51 & 0.28 \\
\hline TELEOSTEI + & $0=$ & $3 \times 21$ & & & & $=$ & 4.65 & 4.16 & 2.63 & 19.34 & & & 1.38 & 3.24 \\
\hline Escama & $=$ & & & & 5.26 & & 6.98 & & 2.63 & z & 2.22 & & 3.21 & \\
\hline Restos calcários & wat & & & & & & & & & & 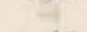 & & 3.21 & \\
\hline TOTAL & 14 & 0.301 & 40 & 9.854 & 38 & 28.023 & 43 & 15.760 & 38 & 7.658 & 45 & 4.376 & 218 & 65.972 \\
\hline
\end{tabular}

(")carapaça em forma de caranguejo

anoitecer, e tarde e noite, decorrente da maior proporção de Penaeidea nas horas de luz e de Brachyura nas horas de escuro. Penaeidea constituiu-se no item principal no período da manhä, e Brachyura nos demais. Brachyura foi representado, principalmente, por jovens de Portunidae (Portunus spinicarpus) e Penaeidea, pelos camarōes Solenoceridae (entre eles Pleoticus mulleri) (Tab. 3).

Semelhante ao verão/88, jovens e adultos apresentaram alta similaridade na frequeência de ocorrência e no peso porcentual dos itens alimentares na fase de atividade alimentar (manhā, tarde e anoitecer). Portanto, as análises ao longo do dia sâo apresentadas para o total da amostra. A composição dos contećdos para o conjunto dos peixes apresentou valores altos de similaridade na fase de atividade alimentar (Tab. 4). Brachyura, Penaeidea e Caridea se apresentaram como presas principais e constantes. Entre os Brachyura destacaram-se os Portunidae e os Leucosiidae. Entre os Penaeidea se destacaram os Sicyoniidae (Sicyona) e os Solenoceridae (Pleoticus mulleri). E entre os Caridea se destacaram os Pasiphaeidae (Leptochela serratorbita).

Em relação às condiçōes oceanográficas, no verāo/87 os valores de temperatura na massa de água do fundo apresentaram pequenas variações ao longo do dia, enquanto que os de salinidade se mantiveram praticamente constantes (Fig. 5a). No verão/88 nenhuma dessas variáveis apresentou variação expressiva (Fig. 5b), e no inverno/ 88 os valores de temperatura e de salinidade da massa de água apresentaram pequenas elevaçōes entre os períodos do amanhecer e manhã (Fig. 5c).

\section{Discussão}

Prionotus punctatus apresentou uma cronologia alimentar que permitiu classificá-la como comedora diurna, com tendência vespertina, de acordo com a nomenclatura de tipos de ritmos alimentares circadianos. Dada a recorrência desta cronologia verificada nas análises realizadas, pode-se levantar a hipótese de ritmo circadiano para esta espécie. $P$. punctatus apresentou ampliação do período de atividade alimentar no verão, que é uma modulação do ritmo circadiano pelo ritmo circanual, cuja recorrência sazonal está relacionada ao fotoperíodo mais longo no verão, em conjunção com condiçōes exógenas tais como condiçōes geofísicas, condições hidrográficas e disponibilidade de alimento; e com condiçōes endógenas (estado reprodutivo, sincronização do estado endocrinológico) (Cloudsley-Thompson, 1980; Cippola-Neto et al., 1988). 


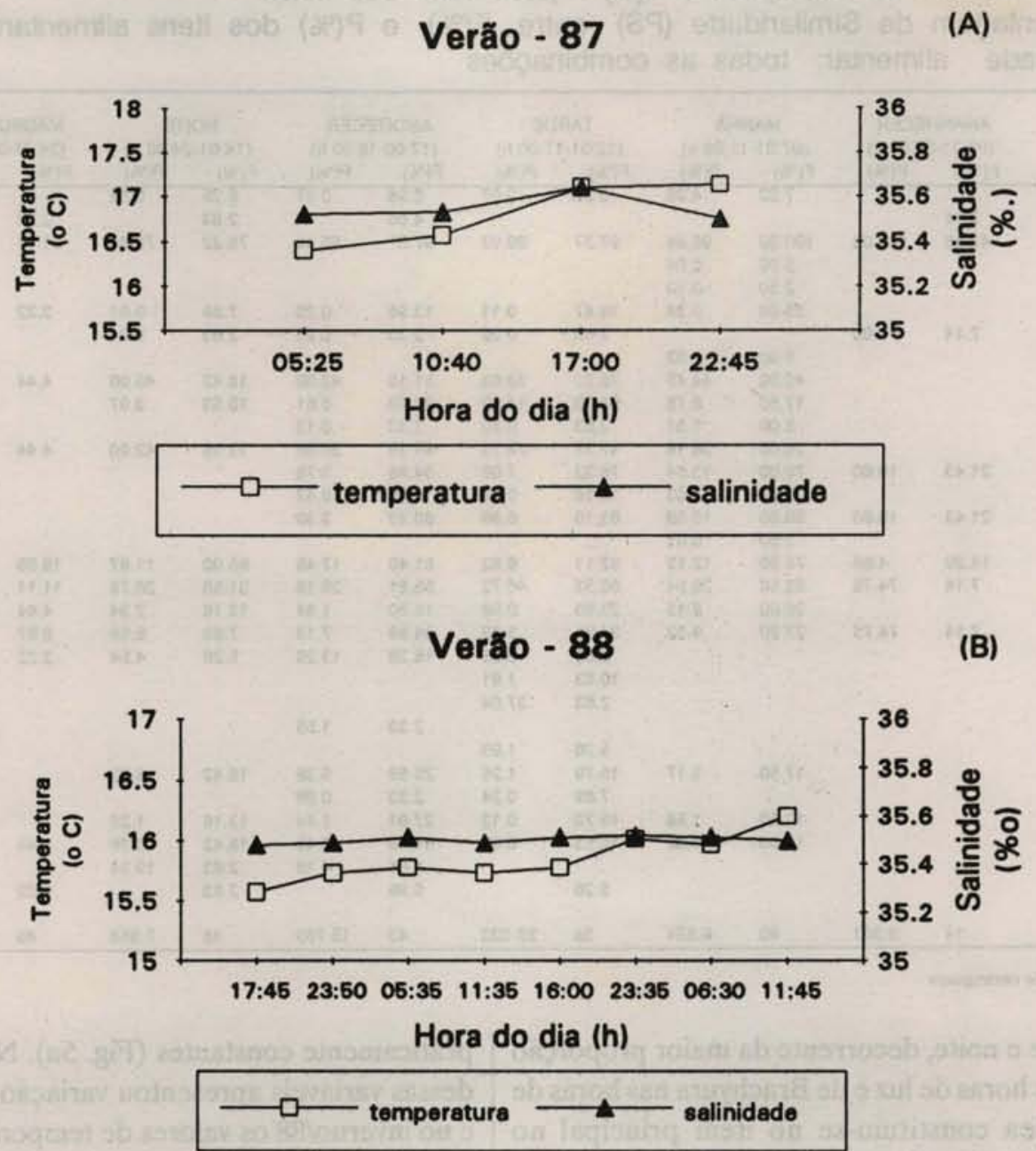

Inverno $-\mathbf{8 8}$

(C)

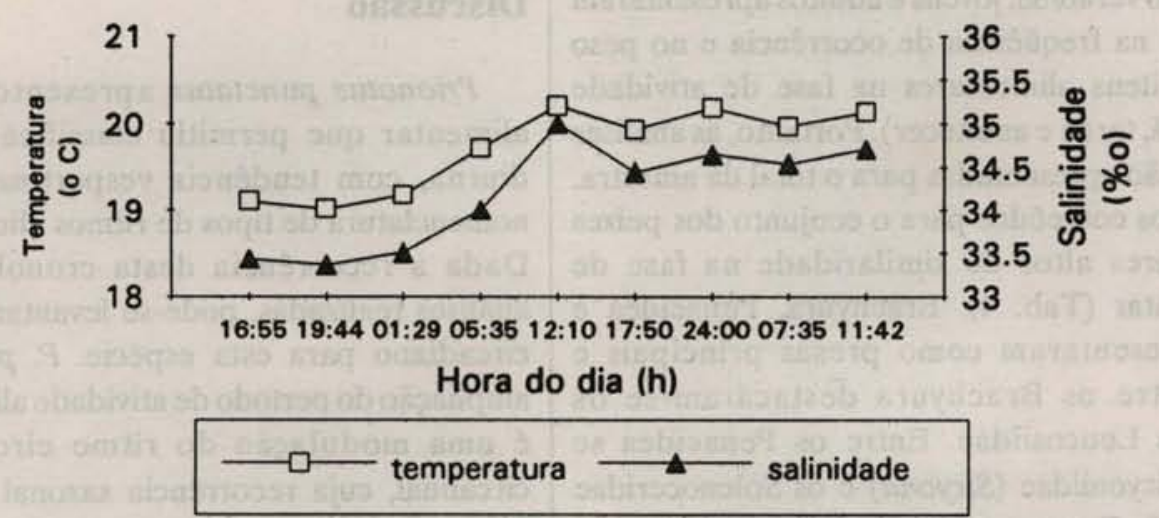

Fig. 5. Temperatura e salinidade da camada de água do fundo no ciclo díário dos períodos de 08 a 10/01/87 (A), de 02 a 04/12/88 (B) e de 22 a $24 / 07 / 88$ (C). 
Há evidências de padrão de atividade alimentar nas horas de luz para esta espécie, na costa do Rio Grande do Sul (Teixeira \& Haimovici, 1989). Este mesmo tipo de atividade alimentar diária foi também verificado para espécies de Triglidae (Prionotus roseus, P. alatus e Bellator brachichir) da plataforma central oeste da Flórida (Ross, 1983). Há, portanto indicações de que o ritmo circadiano na atividade alimentar, proporcionando fase de ingestāo nas horas de luz e fase de repouso nas horas de escuro, seja um padrão generalizado para a família.

Considerando-se os grupos de presas principais deste predador, verificou-se que os estudos sobre a abundância de invertebrados bentônicos ao longo do ciclo diário, evidenciaram que, em geral, camarōes (incluindo Sicyonia tipica) e braquiúros (incluindo Portunus spinicarpus) apresentaram tendência marcante de ocorrência no período noturno, fato que pode estar relacionado com o período de maior atividade das espécies (Pires-Vanin, comun. pess. ${ }^{2}$ ). E em estudos experimentais de laboratório, Carvalho (1992) constatou que o camarão-sete-barbas Xiphopenaeus kroyeri, espécie com biomassa representativa no megabentos da região de Ubatuba (Pires-Vanin, 1989) apresentou maior atividade no período da noite e se manteve em níveis mais baixos de atividade durante o dia, tal qual a maioria das espécies de camarão.

$\mathrm{Em}$ relação às outras presas principais, os camarōes Leptochela (Caridea) e Pleoticus mulleri (Penaeidea), a abundância foi muito baixa na área de estudo (Pires-Vanin, comun. pess. ${ }^{2}$ ), e provavelmente não sejam suscetíveis à captura com os equipamentos de coleta utilizados. Os camarōes Leptochela são considerados como tendo um comportamento intermediário entre os organismos zooplanctônicos e peixes demersais; realizam migraçōes verticais em direção ao fundo, quando sāo consumidos por muitas espécies de peixes demersais (Jones, 1982).

Verificou-se então, que Prionotus punctatus é um peixe com atividade alimentar diurna, com tendência vespertina, e consome presas com atividade noturna. Apresenta movimentos lentos, porém é dotado de excelentes órgãos de sentidos, tais como botōes gustativos nas extremidades dos raios livres das nadadeiras peitorais que utiliza para detecçāo de alimento (Bardach \& Case, 1965). Esta organização temporal presa- predador, com defasagem dos períodos de atividade, poderia ser explicada pela maior vulnerabilidade dessas presas vágeis nos períodos de inatividade, uma vez que o período de alimentaçāo deve estar relacionado com os momentos de maior disponibilidade dos recursos para cada espécie de peixe.

Segundo Bunning (Cipolla Neto et al., 1988), o fator exógeno ou o arrastador mais potente relacionado com o ritmo circadiano é a luz que determina o ciclo de claro e

(2) Pires-Vanin, A. M. S. Instituto Oceanográfico/USP, 1992. escuro. Com certeza, o fator luz atua na atividade alimentar de Prionotus punctatus, pois embora o fotoperíodo seja mais longo no verão em relação ao inverno na latitude de Ubatuba, a zona eufótica do corpo de água da plataforma interna não mostrou um padrão intra-anual evidente, podendo estar iluminado até o fundo nas duas estações climáticas (Aidar, comun. pess. ${ }^{3}$ ).

Além disso, nāo foi verificado entre as propriedades das massas de água presentes no fundo, tanto no veråo quanto no inverno um padrão no ciclo diário que pudesse ser considerado como indício de atuarem como arrastadores. Os valores de temperatura e de salinidade registrados caracterizam a Água Central do Atlântico Sul (água fria e mais salina) presente no verāo e a Água Costeira (água quente e menos salina) presente no inverno, consoante com o padrão sazonal da dinâmica das massas de água que ocupam a área de estudo (Castro Filho et al., 1987).

A composição dos conteúdos estomacais foi semelhante, em termos de ocorrência das presas, nas amostras obtidas durante a fase de atividade alimentar tanto no verão quanto no inverno. No entanto, foram registradas diferenças em termos de peso porcentual, entre as amostras coletadas nestes períodos do dia, nos dois verōes. Estas diferenças podem ser decorrentes da ampliação do período de atividade alimentar de $P$. punctatus, que nesta estação do ano se estende até o período da noite e da disponibilidade das presas. No verāo de $1987, P$. punctatus predou no período da noite Porichthys porosissimus, peixe piscívoro de hábito noturno, comedor de peixes pelágicos (Lane, 1967; Soares et al., 1993), que foi mais importante em termos de peso do que os camarōes Penaeidea e os braquiúros. Já no verão de 1988 a espécie utilizou de modo diferencial os recursos alimentares, camarōes Penaeidea nas horas de claro e braquiúros nas horas crepusculares.

De outro lado foi muito baixa a similaridade da composição dos conteúdos estomacais tanto em termos de ocorrência quanto em termos de peso das presas, na fase de repouso alimentar. Então, do ponto de vista metodológico, é recomendável se estudar a alimentação desta espécie durante o fase de atividade alimentar.

Os alimentos principais de $P$. punctatus, tanto no verão quanto no inverno, foram jovens de siris Portunidae e de camarōes Penaeidea, resultados similares aos observados por Braga \& Braga (1987), para a mesma área. Alguma variaçāo sazonal foi constatada, sendo que no inverno (julho/88), quando é menor a abundância de $P$. spinicarpus (Sartor, 1989), verificou-se um balanço entre Penaeidea e Brachyura; no verāo (janeiro/87 e dezembro/88), quando a abundância de $P$. spinicarpus é expressivamente maior de acordo com Sartor (1989), a importância de Brachyura foi

(3) Aidar, E. Instituto Oceanográfico/USP, 1992. 
relativamente superior. Entre os camarōes se destacaram, em janeiro/87 e julho/88, os camarōes Sycioniidae e, em dezembro/88, os Solenoceridae (Pleoticus mulleri). Entre os braquiuros, em ambas estaçōes climáticas, Portunidae se posiciou como item principal, sendo representado por Portunus spinicarpus no verão e provavelmente por $P$. spinimamus, no inverno (Sartor, 1989).

Em janeiro/87, ́poca em que a estação fixa se localizou em um ponto mais interno da área (Fig. 1) foram registrados, com expressividade em termos de ocorrência, megalopa e jovens de Teleostei. Estas ocorrências, possivelmente, refletiram a distribuição estratificada das presas.

A composição dos conteúdos estomacais da espécie apresenta diferenças geográficas no litoral brasileiro. Os jovens coletados na plataforma do Rio Grande do Sul se alimentaram de pequenos crustáceos (cumáceos, anfípodes, misidáceos e Leptochela serratorbita), enquanto que os exemplares de tamanho maior que $150 \mathrm{~mm}$, e aqueles amostrados na faixa de profundidade superior a 40 m se alimentaram, principalmente, do peixe Porichthys porosissimus (Teixeira \& Haimovivi, 1989). No caso dos resultados obtidos neste trabalho para a costa de São Paulo, não foram observadas diferenças notáveis na composição entre os jovens e adultos que alimentaram-se basicamente de Penaeidea e Brachyura, e além disso, há uma inversão dos resultados com relação à presença de Teleostei, que ocorreu principalmente nos conteúdos dos jovens da faixa mais costeira da amostragem. Observa-se pois, aspectos da estratégia alimentar da espécie consumindo presas, provavelmente, mais abundantes e disponíveis em regiōes geográficas diferentes.

O espectro alimentar e a importância das presas evidenciaram que a cadeia de detrito é a principal via de transferência de energia e produção de Prionotus punctatus, considerando-se que suas presas principais sāo componentes desta cadeia (Paiva, 1990; Petti, 1990). No entanto, há um importe, mesmo que pequeno, de energia do habitat pelágico baseada na produção fitoplanctônica, como pode-se detectar pela presença de megalopa e do peixe Porichthys porosissimus, que é um comedor de peixes pelágicos (Soares et al., 1993). Este é um quadro típico da trofodinâmica de plataforma continental interna, onde há um compromisso entre o pelagial e o bentos (Longhurst \& Pauly, 1987).

Do ponto de vista de transferência de energia, esta parece ser a localização trófica generalizada das cabrinhas (Triglidae), como se verificou para uma espécie do Mediterrâneo ocidental (Moreno \& Matallanas, 1983), para 11 espécies da plataforma oeste da Flórida (Ross, 1983, 1986) e 2 espécies da plataforma do Rio Grande do Sul (Teixeira \& Haimovici, 1989).

\section{Conclusões}

A cabrinha, Prionotus punctatus, apresenta hábito alimentar diurno, com tendência vespertina, podendo-se levantar a hipótese de ritmo circadiano na sua atividade alimentar. Concluiu-se também que a composição e a importância dos itens alimentares do alimento varia ao longo do ciclo diário, apresentando maior similaridade na fase de atividade alimentar. Para o estudo ou monitorização da alimentação da espécie deve-se tomar amostras durante a fase de atividade alimentar, que ocorre nas horas iluminadas e crepusculares do dia. Em relação à transferência de energia, a espécie participa principalmente da cadeia de detrito, consumindo siris, camarōes-pedra e camarão vermelho, invertebrados bentônicos da epifauna.

\section{Referências bibliográficas}

BARDACH, J. E. \& CASE, J. 1965. Sensory capabilities of the modified fins of squirrel hake (Urophycis chues) and searobins (Prionotus carolinis and $P$. evolans). Copeia, (2):194-206.

BARNES, R. D. 1984. Zoologia dos invertebrados. São Paulo. Roca, 1179p.

BERG, J. 1979. Discussion of methods of investigating the food of fishes, with reference to a preliminary study of the prey of Gobiusculus flavescens(Gobiidae). Mar. Biol., 50:263-273.

BOWEN, S. H. 1983. Quantitative description of the diet. In: Nielsen, L. A. \& Johnson, D. L., eds Fisheries techniques. Maryland, American Fishery Society. p. 325-336.

BRAGA, F. M. de S. \& BRAGA, A. M. de S. 1987. Estudo do hábito alimentar de Prionotus punctatus (Bloch, 1797) (Teleostei, Triglidae) na regiâo da Illha Anchieta, Estado de São Paulo, Brasil. Revta. brasil. Biol., 47(1/2):31-36.

CARVALHO, P. S. M. de 1992. Bioenergética do camaräo-sete-barbas Xiphopenaeus kroyeri (Heller, 1862). Avaliação do metabolismo, excreção de amônia e calorimetria. Dissertação de mestrado. Universidade de São Paulo, Instituto Oceanográfico. $206 \mathrm{p}$.

CASTRO FILHO, B. M. de; MIRANDA, L. B. de \& MIYAO, S. Y. 1987. Condiçōes hidrográficas na plataforma continental ao largo de Ubatuba: variaçōes sazonais e em média escala. Bolm Inst. oceanogr., S Paulo 35(2):135-151. 
CIPOLLA-NETO, J.; MARQUES, N. \& MENNA BARRETO, L. 1988. Introduçāo ao estudo da cronobiologia. São Paulo, Ícone. 270 p.

CLARK, M. R. 1985. Feeding relationships of seven fish species from the Campbell Plateau, New Zealand. N.Z. J1. mar. Freshwat. Res., 19(3):365-374.

CLOUDSLEY-THOMPSON, J. L. 1980. Biological clocks; their functions in nature. London, Weidnfeld \& Nicolson. 138p.

DAAN, N. 1973. A quantitative analysis of the food intake of North Sea cod Gadus morhua. Neth. J. Sea Res., 6(4):479-517.

FIGUEIREDO, J. L. \& MENEZES, N. A. 1980. Manual de peixes marinhos do sudeste do Brasil. III.Teleostei (2). São Paulo, Museu de Zoologia da Universidade de São Paulo. 90 p.

GLOVA, G. J. \& SAGAR, P. M. 1991. Dietary and spatial overlap between stream populations of a native and two introduced fish species in New Zealand. Aust. J. mar. Freshwat. Res., 42:423- 433.

HYSLOP, E. J. 1980. Stomach contents analysis- a review of methods and their application. J. Fish Biol., 17(4):411-429.

JAMES, A. G. 1987. Feeding ecology, diet and field-based studies on feeding selectivity of the cape anchovy Engraulis capensis Gilchlist. In: Payne, A. I. L.; Gulland, J. A. \& Brink, K. H., Eds The Benguela and comparable frontal systems. S. Afr. J. mar. Sci., 5:673-692.

JONES, R. 1982. Ecosystems, food chain and fish yields. In: Pauly, D. \& Murphy, G. I., eds Theory and management of tropical fisheries. ICLARM Conf. Proc., (9):195-239.

LAGARDERE, J.P. 1987. Feeding ecology and daily food consumption of common sole, Solea vulgaris Quensel, juveniles on the French Atlantic coast. J. Fish Biol., 30(1):91-104.

LANE, E. D. 1967. A study of the Atlantic midshipsman Porichthys porosissimus in the vicinity of Port Aransas, Texas. Contr. mar. Sci. Univ. Texas, 12:1-53.

LIVINGSTON, R. J., 1982. Trophic organization of fishes in a coastal seagrass system. Mar. Ecol.-Prog. Ser., 7(1):1-12.

LONGHURST, A. R. \& PAULY. D. 1987. Ecology of tropical oceans. San Diego, Academic Press. 407 p.
MacPHERSON, E. \& ROEL, B. A. 1987. Trophic relationships in the demersal fish community off Namibia. In: Payne, A. I. L.; Gulland, J. A. \& Brink, K. H., eds. The Benguela and comparable frontal systems. S. Afr. J. mar. Sci., (5):585-596.

MENEZES, N. A. \& FIGUEIREDO, J. L. 1980. Manual de peixes marinhos do sudeste do Brasil. IV. Teleostei (3). Sāo Paulo, Museu de Zoologia da Universidade de São Paulo. 96 p.

MORENO, R. \& MATALLANAS, J. 1983. Etude du regime alimentaire de Lepidotrigla cavillone (Lacèpede, 1801) (Pisces, Triglidae) dans la mer catalane. Cybium, 7(3):93-103.

NONATO, E.F.\& AMARAL, A. C. Z. 1979. Anelídeos poliquetas. Chaves para Familias e Gêneros. Instituto Oceanográfico da USP, Edição dos Autores. 78p.

PAIVA, P. C. de. 1990. Padrōes de distribuição e estrutura trófica dos anelídeos poliquetas da plataforma continental do litoral norte do Estado de São Paulo. Dissertação de mestrado. Universidade de São Paulo, Instituto Oceanográfico. 146 p.

PARRISH, D. L. \& MARGRAF, F. J. 1990. Gastric evacuation rates of white perch, Morone americana determined from laboratory and field data. Environ. Biol. Fishes, 29:155-158.

PETTI, M. A. V. 1990. Hábitos alimentares dos crustáceos decápodos braquiúros e seu papel na rede trófica do infralitoral de Ubatuba (litoral norte do Estado de São Paulo, Brasil). Dissertação de mestrado. Universidade de São Paulo, Instituto Oceánográfico. 150 p.

PIRES-VANIN, A. M. S. 1989. Estrutura e dinâmica da megafauna bêntica na plataforma continental da região norte do Estado de São Paulo, Brasil. Tese de livre-docência. Universidade de São Paulo, Instituto Oceanográfico. $172 \mathrm{p}$.

ROCHA, G. R. A. 1990. Distribuiçāo, abundância e diversidade da ictiofauna na região de Ubatuba-SP (23⒉' S- $\left.24^{\circ} 00^{\prime} \mathrm{S} ; 4^{\circ} 30^{\prime} \mathrm{W}-45^{\circ} 30^{\prime} \mathrm{W}\right)$, Brasil. Dissertação de mestrado. Universidade de Sāo Paulo, Instituto Oceanográfico. 2v.

ROSS, S. T. 1983. Searobins (Pisces:Triglidae). Mem. Hourglass cruises, 6(4):76 p.

1986. Resource partitioning in fish assemblages: a review of field studies. Copeia, (2):352-388. 
SARTOR, S. 1989. Composiçāo e distribuição dos Brachyura (Crustacea, Decapoda) no litoral norte do Estado de São Paulo. Tese de doutorado. Universidade de São Paulo, Instituto Oceanográfico. 197 p.

SCRIMGEOUR, G. J. \& WINTERBOURN, M. J. 1987. Diet, food resource partitioning and feeding periodicity of two riffle- dwelling fish species in a New Zealand river. J. Fish Biol., 31(3):309-324.

SIEGEL, S. 1981. Estatística não-paramétrica (para ciências do comportamento). São Paulo. McGraw-Hill do Brasil. 350 p.

SOARES. L. S. H.; GASALLA, M. A.; RIOS, M. A. T.; ARRASA, M. V. \& ROSSIWONGTSCHOWSKI, C. L. D. B. 1993. Grupos tróficos de 11 espécies dominantes de peixes demersais da plataforma continental interna de Ubatuba, Brasil. Publção esp. Inst. oceanogr., S Paulo, (11):189-198.

TEIXEIRA, R. L. \& HAIMOVICI, M. 1989. Distribuiçāo, reprodução e hábitos alimentares de Prionotus punctatus e $P$. nudigula (Pisces:Triglidae) no litoral do Rio Grande doSul, Brasil. Atlântica, Rio Grande, 11(1):13-45.

TUlly, O. \& CEIDIGH, P. O. 1989. The ichthyoneuston of Galway Bay (West of Irland). II. Food of post-larval and juvenile neustonic and pseudoneustonic fish. Mar. Ecol.-Prog. Ser., 51(3):301-310.

VAZZOLER, A. E. A. DE M.; ROSSIWONGTSCHOWSKI, C. L.D. B.;SANTORO, E. C. \& LIZAMA, M. A. 1988. Reproduçāo de teleósteos demersais em um ecossistema costeiro da regiāo de Ubatuba, São Paulo, Brasil. In: SIMPÓSIO DA FURG SOBRE PESQUISA PESQUEIRA, 1., Rio Grande, 1989. Resumos. Rio Grande, Fundação Universidade do Rio Grande. p.61.
WALLACE JR, R. K. 1981. An assessment of diet-overlap indexes. Trans. Am. Fish. Soc., 110:72-76.

WEATHERLEY, A. H. 1972. Growth and ecology of fish populations. London, Academic Press. 293 p.

WEATHERLEY, N. S. 1989. The diet and growth of 0-group flounder, Platichthys flesus (L), in the River Dee, North. Hydrobiologia, 178:193-198.

WILLIAMS, A. B. 1984. Shrimps, lobsters and crabs of the Atlantic coast of the eastern United States, Maine to Florida. Washington, D. C. Smithsonian Institution Press. 550p.

WINDELL, J. T. \& BOWEN, S. H. 1978. Methods for study of fish diets based on analysis of stomach contents. In: Bagenal, T., ed. Methods for assessment of fish production in freshwaters. Oxford, Blackwell. p.197-203.

ZAR, J. H. 1984. Biostatistical analysis. Englewood Cliffs, N.J., U.S., Prentice-Hall. 718p.

(Manuscrito recebido 11 agosto 1993; revisto 30 março 1994; aceito 20 novembro 1994) 